\title{
INTEGRATED PROCESS SIMULATION AND DIE-DESIGN IN SHEET METAL FORMING
}

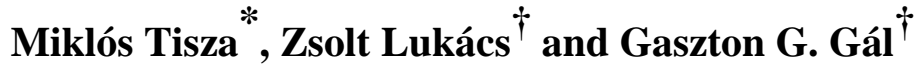 \\ * Department of Manufacturing Engineering \\ University of Miskolc \\ 3515 Miskolc-Egyetemváros, Hungary \\ e-mail: mettsz@uni-miskolc.hu,web page: http://www.met.uni-miskolc.hu \\ $\dagger_{\text {Metal Forming Division }}$ \\ University of Miskolc \\ 3515 Miskolc-Egyetemváros, Hungary \\ e-mail: lzsolt@kugli.met.uni-miskolc.hu, web page: http://www.met.uni-miskolc.hu
}

Key words: process simulation, die design, FEM integration

Summary. During the recent 10-15 years, Computer Aided Process Planning and Die Design evolved as one of the most important engineering tools in sheet metal forming, particularly in the automotive industry. This emerging role is strongly emphasized by the rapid development of Finite Element Modelling, as well. The purpose of this paper is to give a general overview about the recent achievements in this very important field of sheet metal forming and to introduce some special results in this development activity. Therefore, in this paper, an integrated process simulation and die design system developed at the University of Miskolc, Department of Mechanical Engineering will be analysed. The proposed integrated solutions have great practical importance to improve the global competitiveness of sheet metal forming in the very important segment of industry. The concept described in this paper may have specific value both for process planning and die design engineers.

\section{INTRODUCTION}

In the recent years, the role and importance of metal forming processes in manufacturing industry have been continuously increasing primarily due to its material- and cost-effective nature. It is further emphasised by the recent advances in tools, materials and design, which in turn provide significant improvements in the mechanical properties and tolerances of the products. Moreover, in the recent years metal forming develops in the direction of net-shape or near-net-shape manufacturing to reduce the need for subsequent machining operations and to minimise the total manufacturing cost. Consequently, in metal forming both the process planning and the tool design represent very important and complex tasks.

The global competition also requires that manufacturing industry - besides the skill and the experience accumulated in the shop practice - should increasingly utilise proven techniques of Computer Aided Engineering for rapid and cost effective process design and tool manufacturing. The application of various methods of Computer Aided Engineering has become one of the most important topics in manufacturing industries and particularly in the automotive industry. 
The application of various CAE techniques practically covers the full product development cycle from the conceptual product design through the process planning and die design up to the manufacturing phase of the production. CAE techniques are widely used in sheet metal forming, for example to predict the formability, to determine the type and sequences of manufacturing processes and their parameters, to design forming tools, etc. The importance of the application of CAE tools becoming more and more important as the manufactured parts are becoming ever increasingly complex. As the need for the widespread application of CAE techniques driven by the demand of global competitiveness accelerates, the need for a robust and streamlined Process and Die Design Engineering (PDDE) becomes more and more crucial.

Recently, there are two main approaches to achieve these goals. One of them is the application of knowledge-based expert systems, which are generally based on simplified plasticity theory and empirical technological rules. There are a great number of papers dealing with the use of knowledge-based systems both in sheet and bulk metal forming [1-3]. However, the exclusively knowledge based solutions have certain disadvantages: they usually cannot provide an enough accurate solution to the problem since these systems are generally based on simple technological rules with limited validity. Therefore knowledge-based systems cannot predict for example the material flow, and usually cannot provide the accurate stress and strain distribution inside the component.

As another approach, numerical techniques (recently mainly finite element modeling) are applied for the analysis of the plastic deformation [4-6]. The main objectives of the application of numerical process simulation in metal forming are to determine appropriate process parameters and to develop adequate die design by process simulation, to improve part quality by predicting process limits and preventing flow induced defects. Besides these, numerical process simulation also leads to reducing process and die try-out, as well as shorter lead times, while significantly reducing manufacturing costs. But the exclusive use of numerical modeling - like it is the case in the exclusive use of knowledge-based systems has also some drawbacks, too. In spite of the enormous development of hardware and software facilities, the reliability of results is often dependent on the experiences of the user. It is partly due to the large number of operating parameters whose influence should be investigated, and partly due to the numerical difficulties caused by the complexity of the applied mathematical model to describe the material behavior. Therefore, in the recent years the integration of these two fields (i.e. the knowledge-based systems and numerical modeling) has gained primary importance [7].

In this paper, the integration of various CAE techniques as Knowledge and Simulation Based Systems (KSBS) will be described through the example of sheet metal forming practice. For better understanding of knowledge and simulation based systems, first a short historical overview of CAE evolution in metal forming will be given. Furthermore, the conventional and simulation based process planning and tool design will be shortly compared.

\subsection{Knowledge Based Systems in Sheet Metal Forming}

Sheet metal forming is one of the most widely applied manufacturing processes in manufacturing industry. Parts made from sheet metal can provide, with appropriate design, a high strength to weight ratio. They are increasingly used from small electrical components through the automobile industry up to large aircraft structures. Despite the increasing number of applications of sheet metal parts, surprisingly little quantitative design information is available in the technical literature. Most companies use internal guidelines for part design, based on experience with the geometries and materials used in that specific company. While such design guidelines are extremely useful and practical, they do not necessarily consider in detail the fundamental reasons for selecting a given design. Thus, when a new part, a new 
material, or a new process is introduced the entire set of experience-based design guidelines must be re-evaluated and modified. Therefore, it is necessary to develop generic design methods based on metal forming analysis and on systematic experimental investigation. This tendency can be clearly observed in the development of various knowledge-based systems for designing sheet metal parts and for process planning of forming procedures. As in many other metal forming applications, process planning and design of dies for sheet forming can benefit from a combined application of knowledge based systems and process modeling. Recently,

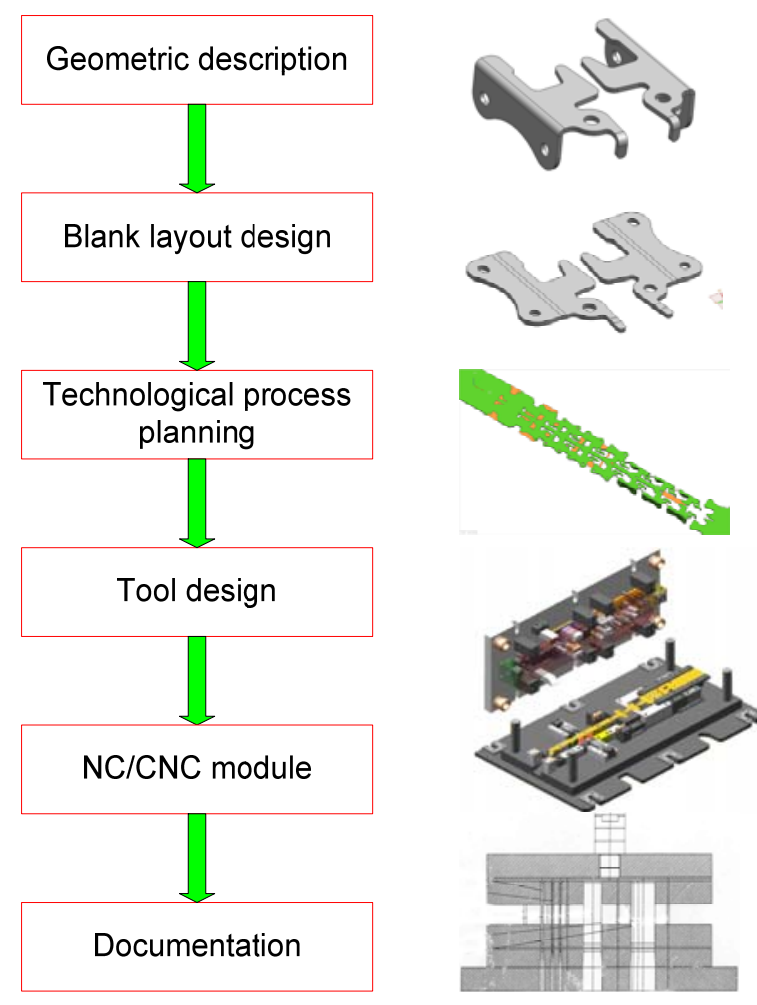

Fig. 1. Conventional process planning and die design in CAD environment many companies are applying $\mathrm{CAD} / \mathrm{CAM}$ techniques and knowledge-based expert systems to improve and partially automate die design and manufacturing function.

Several program packages were elaborated for metal forming processes at the University of Miskolc at the Department of Mechanical Engineering. Among them, first a general CAD/CAM system for the process planning of sheet forming processes performed in progressive dies should be mentioned [8]. The general scheme of this knowledge based expert system can be seen in Fig. 1.

In this system, the process planning and the die-design functions are integrated into a knowledge-based expert system. It has a modular structure with well defined tasks of each module and providing streamlined data and information flow between the various modules. It consists of a geometric module for creating, exporting and importing the object geometry, a blank module for determining the optimum shape, size, and nesting of blanks, a technological design module for designing the process sequence based on empirical rules and technological parameters, a tool design module for designing the tools and selecting a tool of standard size, and an $\mathrm{NC} / \mathrm{CNC}$ post processor module for preparing programs for $\mathrm{NC} / \mathrm{CNC}$ manufacturing of tool elements.

\subsection{Finite Element Modelling and Simulation in Metal Forming}

The forming simulation in sheet metal forming technology and its industrial applications have greatly impacted the automotive sheet metal product design, die developments, die construction and tryout, and production stamping in the past decade [10]. It led to significant progresses not only in fundamental understanding of sheet metal formability, forming mechanics, numerical methods, but also to the fruitful industrial applications in a wide range of industrial production [11].

The automotive die and stamping industry benefit most from the stamping simulations. The technology advancement speeds up the historical transition in automotive die development and stamping from a tryout-based workshop practice to a science-based, technology-driven engineering solution. The applications and benefits may be summarized as follows [12]:

- Stamping simulation is used as a Design for Manufacturability (DFM) tool to assess and validate the product styling surface designs to ensure a formable sheet product design. 
- It may be used as a die engineering tool in stamping die developments.

- It may be used as a tryout tool to shorten production die tryout and thus to significantly reduce die cost and lead-time.

- It may be used as a production tool to provide production stamping conditions (beads, lube, binder and press forces, etc.).

- It may be used as a problem solving tool for production troubleshooting to reproduce manufacturing problems, and to provide solutions for process control improvements.

- It may be used as a simulation-based manufacturing guide to use the simulation output to drive consistency among die engineering, die construction, and production stamping.

- Finally, the stamping simulation may be used as a learning tool to explore and gain new knowledge and application guidance for new forming techniques and new materials.

Stamping simulation development and industrial applications have been evolving in three main stages, namely: (1) the fundamental research and primary laboratory works in 1970s1980 s, (2) the early industrialization, i.e. pioneer industrial trials in the early 1990s, and (3) the mass production applications after the mid 1990s.

In today's die and stamping industry, the simulation for virtual validations of die developments before production trials is a critical business for lead-time reduction, cost reduction and quality improvements. The global competitions drive higher quality requirements, lower cost, and shorter lead-time. The competitions also drive the industry to use more new designs, new materials, and new forming processes. These trends in automotive stamping can be summarized as follows [13].

- Increasing part size and shape complexity such as whole body side panels, and multiple attached parts formed in one die to improve productivity and reduce die cost.

- Increasing material diversity to meet different needs such as using light weight material (aluminum) for fuel economy, using stronger material for safety (dual phase steel, TRIP steel, and ultra high strength steels), using laminated metal-plastic-metal sheets for noiseand vibration reduction, and using tailor-welded blank to reduce the number of parts for better structure integrity.

- Increasing use of unconventional forming processes such as hydro-forming for extra deep drawn panels, superplastic forming for complicated parts, and forming with intermediate annealing for materials very difficult to form.

All these new trends create new challenges for stamping simulation from fundamental research to software development and to production applications [14].

\section{PROCESS PLANNING AND DIE-DESIGN IN SHEET METAL FORMING}

One of the main drawbacks in industrial practice hindering the even more wide application of simulation techniques that the output results of simulation packages are not usually directly and easily usable for computer aided die design. Obviously, there are tremendous efforts to successfully link CAD and FEM systems, however, still there are a lot to do in this field [17]. This solution requires a fully integrated approach of computer aided product design, process planning and die design, as well as the finite element simulation of the forming processes. It means that simulation tools should be efficiently used throughout the whole product development cycle [18].

This concept will be illustrated through the examples of automotive part production. In our practice, we use Unigraphics NX 4 as a CAD system for supporting the Process Planning and Die Design tasks and the AutoForm 4.05 is used as the numerical simulation tool, however, the principles applied here can be similarly adopted by using different CAD and simulation packages, too. Before analyzing this integrated solution, let's summarize the main features of forming process planning and die design in so-called conventional CAD environment. 


\subsection{Process planning and die design in conventional CAD environment}

Stamping industry applies CAD techniques both in the process planning and die design already for many years. However, in a ,traditional" CAD environment, these are practically stand-alone solutions, i.e. for example a knowledge based process planning solution is applied for the determination of the necessary types of forming processes, even in some cases, the forming sequences can be determined in this way together with the appropriate process paramteres, too. After determining the process sequences and process parameters, the forming dies are designed using sophisticated CAD systems, however, still we do not have any evidence whether the designed tools will provide the components with the prescribed properties. Therefore, before it goes to the production line, usually a time- and cost consuming try-out phase follows, as it is shown in Fig. 2

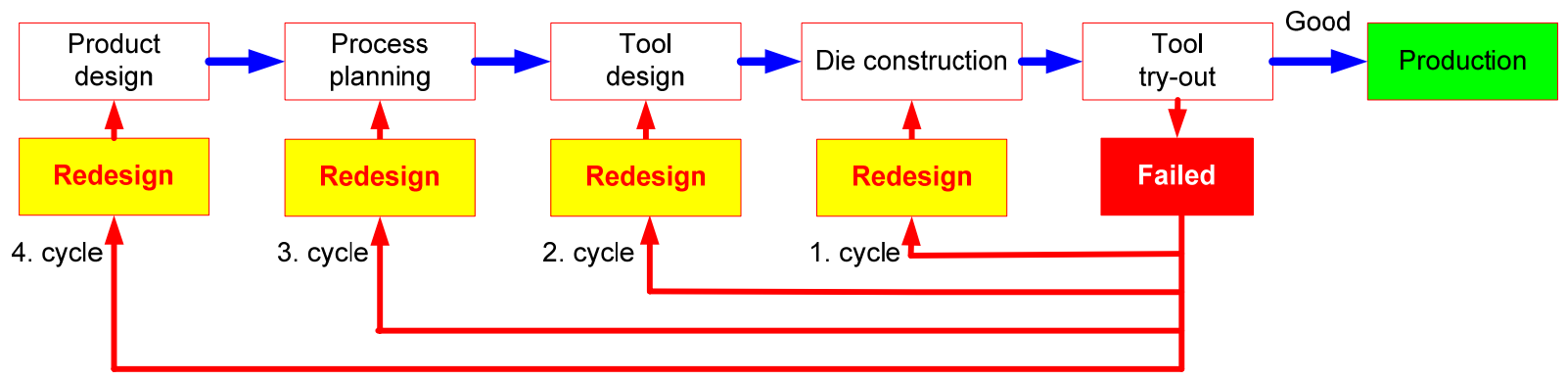

Fig. 2. Flow chart of process planning and die design in traditional CAD environment

If the try-out is successful, i.e. the die produces parts with no stamping defects, it will be sent to the stamping plant for production. On the other hand, if splitting or wrinkling occur during the tryout, the die set needs to be reworked. It means that we have to return first to rework the die construction by changing the critical die parameters (e.g. die radii, drawing gap, etc.). If it does not solve the problem, a new die design, or a new process planning is required. Some cases, we have to go back even to the product design stage to modify the product parameters. The more we go back the higher the development and design costs are. Occasionally, the die set is scraped and a perfectly new product-, process- and die design is needed. As a result, die manufacturing time is increased as well as the cost of die making.

\subsection{Simulation based process planning and die design}

Due to the global competition - and this is particularly valid for the automotive industry there is an overall demand to improve the efficiency in both the process planning and in the die design phase, as well as to reduce the time and product development costs and to shorten the lead times. It requires the efficient use of simulation techniques from the earliest stage of product development, to give feedback from each step to make the necessary corrections and improvement when it takes the least cost [19]. This principle is illustrated in the schematic flow chart of simulation based process planning and die design as shown in Fig. 3.

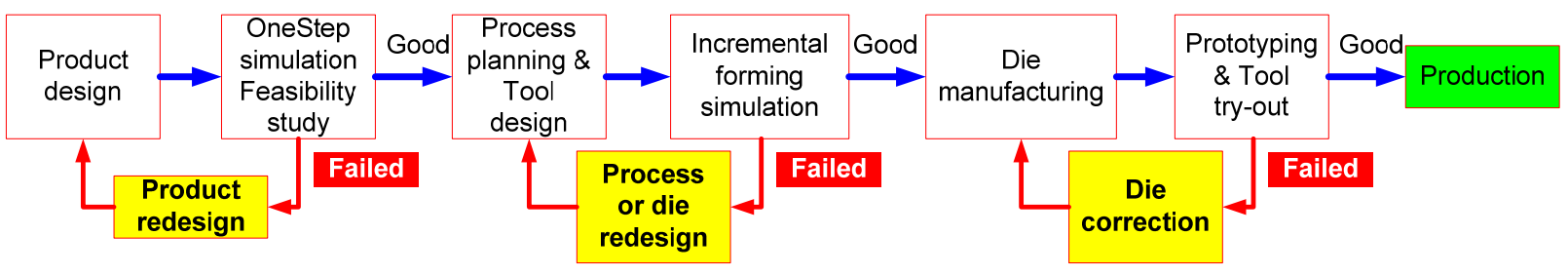

Fig. 3. Workflow in simulation based process planning and die design

With this approach, stamping defects may be minimized and even eliminated before the 
real die construction stage. If any correction or redesign is needed, it can be done immediately, with a very short feedback time, thus it leads to a much smoother die try-out if necessary at all, and to significantly shorter lead times with less development costs.

However, even with this approach, there are some further shortfalls in the die design process, since most of the simulation programs do not provide die construction in sufficient details, which can be easily used in most of the CAD systems to complete the die design task. This shortage may be overcome by integrating the CAD and FEM systems through a special interface module which can provide a smooth, continuous and reliable data exchange between the two important parts of design process.

\section{SIMULATION AND KNOWLEDGE BASED SYSTEMS - AN INTEGRATED APPROACH}

As it was mentioned before, this solution will be described through the example of an automotive sheet metal component using the Unigraphics NX (version 4.0) as the CAD system, and the AutoForm 4.05 as the FEM package, however, the principles applied here, can be adopted to other programs as well [20].

The selection of these two program packages can be explained by several reasons. On the one hand, both the Unigraphics and the AutoForm are among the most widely applied packages in the automotive industry in the World. On the other hand, these two systems are among the first to offer a special interface module to enhance the information and data exchange between CAD modelling and FEM simulations in both directions making possible the most efficient integration during the whole product development cycle. In the forthcoming sections, this solution will be described in detail following the road map of this simulationguided process planning and die design procedure.

\subsection{Geometric modelling of the sheet metal component}

The CAD model of the component created by the product design engineer is shown in Fig.

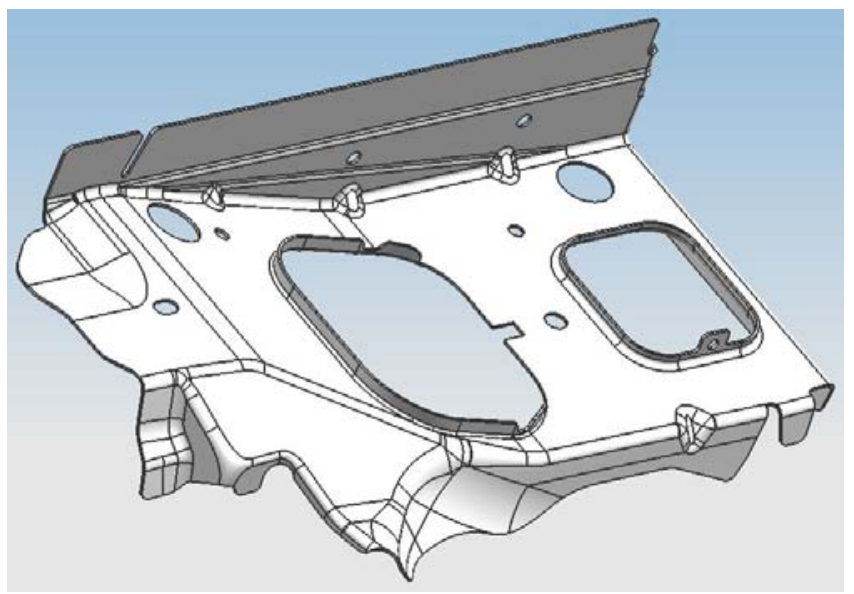

Fig. 4. CAD model of the component to be manufactured
4. As it often happens in the automotive industry, the component has a symmetric counterpart (so-called left and right handed or double attached parts).

The part model is created in Unigrapics as a solid model. However, FEM systems dedicated for sheet metal forming usually require surface models. Therefore, before exporting the part model a surface model should be created. This function is wellsupported in most CAD systems. Depending on the simulation requirements, even we can decide which surface (top, middle or bottom) will be exported into the surface model.

\subsection{Feasibility of the component formability}

In most cases, process planning engineers would like to know right at the beginning whether the component can be manufactured with the planned formability operations. Therefore, after importing the surface model of the component with the AutoForm input generator, first a fast feasibility study should be performed. 
The AutoForm has an extremely well suited module for this purpose: in the so-called OneStep simulation module, this formability analysis can be done even if we do not have any, or just very few information on the forming tools. Using this One-Step simulation procedure, a

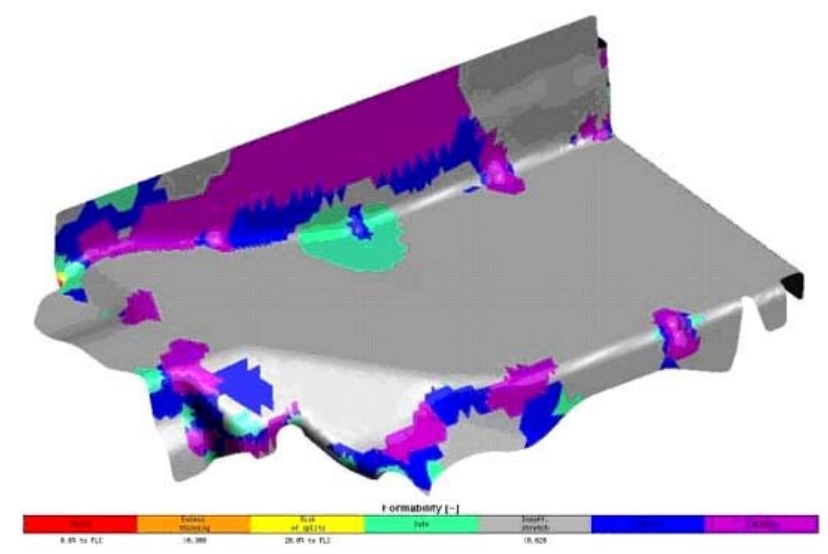

Fig. 5. One-Step formability study of the part quick decision can be made if any modification of the part is required.

Besides the part formability validation in this very early stage of product development, further important possibilities are also offered in this module including the analysis of slight part modifications, studying alternative material types and grade, or various thicknesses, material cost estimation and optimization, etc.

If this feasibility study is successful (see for example for this component in Fig. 5.) the work of process planning engineer can be efficiently supported by determining the optimum blank shape and sizes.

\subsection{Determination of the optimum blank}

The optimum blank determination is particularly important when we have such a complicated part, where besides the expected intricate contour line, we have to consider the joined shape of left and right handed, double attached parts, as well. The precise determination of optimum blank is important from other points of view as well.

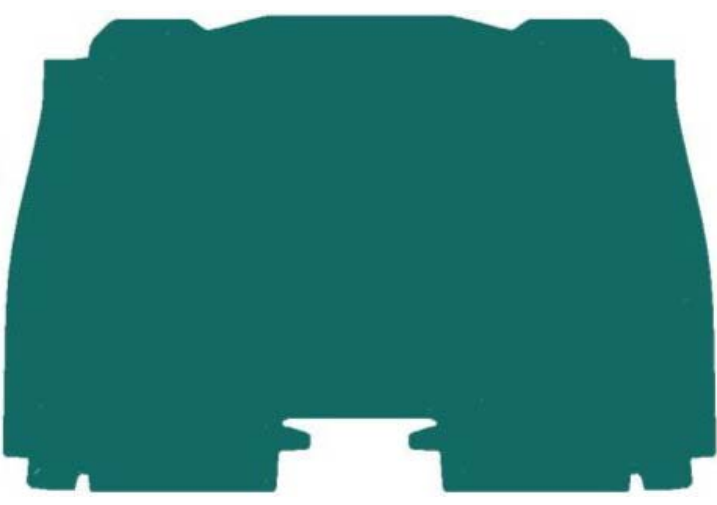

Fig. 6. The optimum blank trimmed for the final shape

As it can be seen from the CAD model of the part (Fig. 4.), a trimming operation is practically impossible when the part is already formed due to its complex 3D part boundary line. Therefore, we have to apply a blank geometry which does not need any trimming operation in spite of the complicated 3D forming operations, i.e. when the forming is finished, we have the required part boundary line within the prescribed tolerances. The blank shape determined for the joined left and right handed parts is shown in Fig. 6.

Furthermore, this optimum blank is also necessary for the determination of material utilization, which can be done in the Nesting and Blank-layout module. This is also important starting information for the detailed, incremental forming simulation.

\subsection{Detailed incremental process simulation and simulation based die design}

Even if the One-Step simulation resulted in good formability, the final decision on the whole process realization can be made only after performing a detailed incremental modeling particularly concerning the critical forming steps. For this detailed simulation we need already very detailed knowledge on the tools and process parameters. The active surfaces of the forming tools can be derived from the imported surface model of the component to be produced utilizing the many useful possibilities offered by the Die-Designer module to create the binder and addendum surfaces, as well as the so-called reference surface, which can be used to quickly derive the punch and die surfaces, as well. Applying this simulation tool 


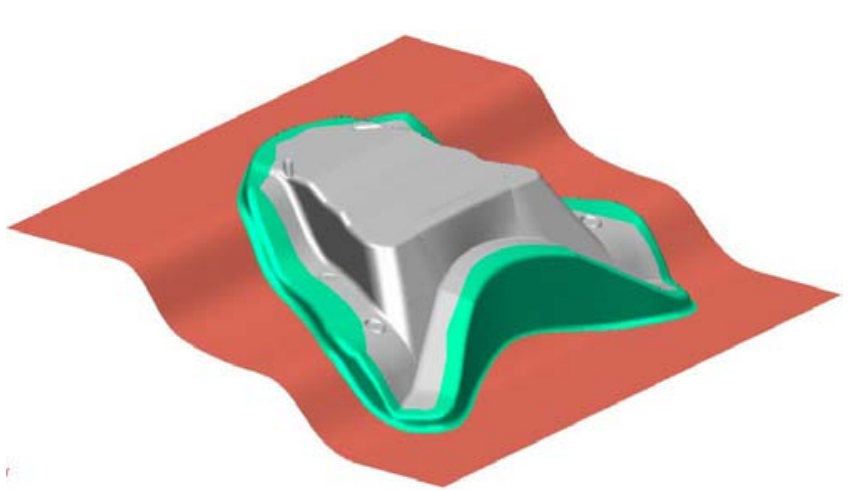

Fig. 7. Modified reference surface to derive the tool surfaces

The simulation tool setup determined with the Die-Designer module for this component can be seen in Fig. 8., after some minor modifications. Obviously, similarly to the part model, the simulation tools are surface models, too.

Even with the modified binder and addendum surface, and changing some process conditions, with this setup we could not achieve a perfect, defectless part due to the excessive stretching at the die radius shown in Fig. 10.

This problem was solved by applying so-called free cut-off lines in the middle of the double attached part, which is in the scrap region after separating the left and right parts. This modification resulted in a defect-free component as shown in Fig. 9.

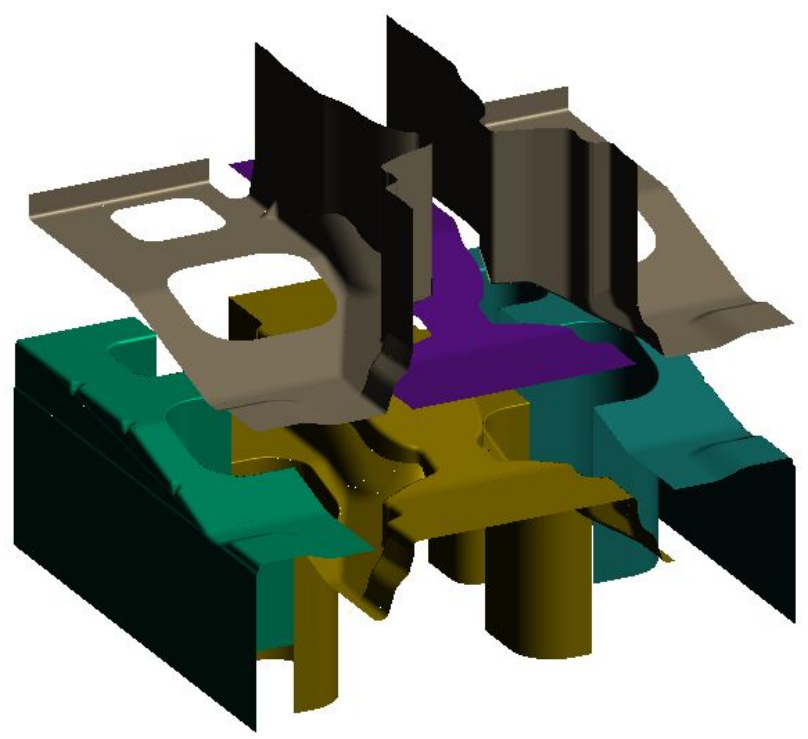

Fig. 8. Simulation tool setup for the incremental process simulation
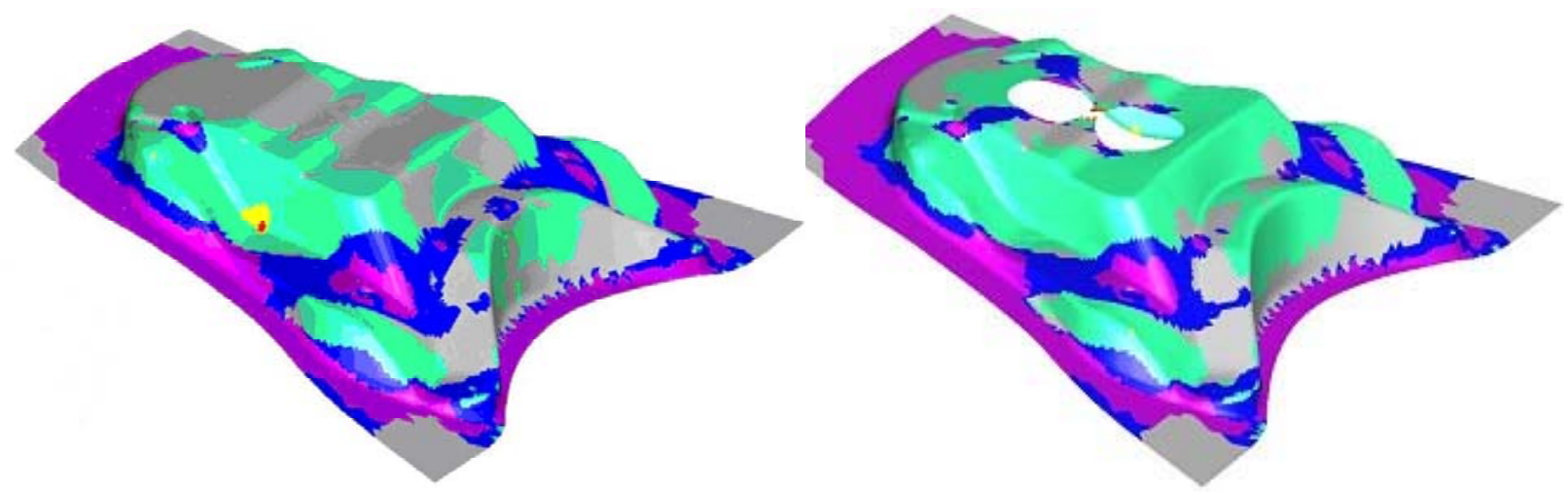

Fig. 10. Cracks arising at die radius due to Fig. 9. Defect free double attached part with cutexcessive stretching 
After getting the defect free component with some tool and process parameter changes, we can complete the die design task on the basis of simulation results. For this purpose, the final reference geometry is exported to the Unigraphics CAD system to design the complete tool assembly. In this case, we have the reverse problem, as we had when importing the part model. For the tool design we need solid models: however, the exported reference geometry is a surface model, which should be converted to a solid one. In Fig. 11., the solid model of the punch, whilst in Fig. 12. the solid model of the die can be seen. When these active tool elements are derived, the complete tool assembly can be created using the design capabilities of the Unigrapics CAD system.

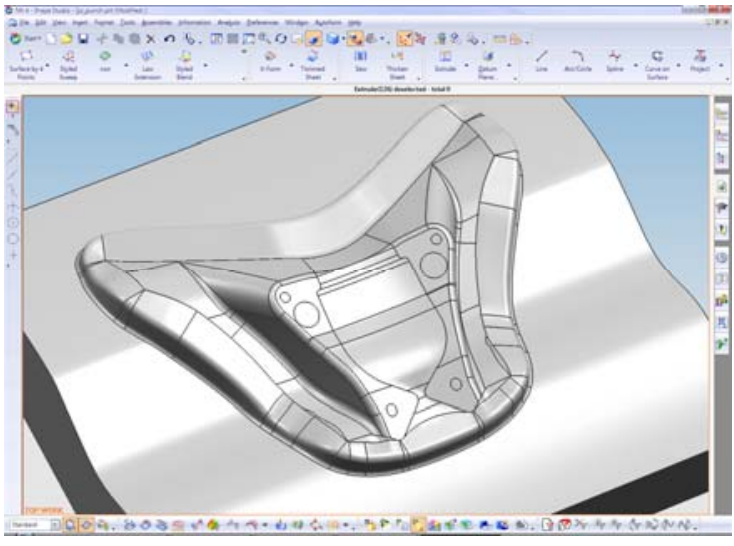

Fig. 11. Solid model of the punch created from the reference geometry using the AFUG interface

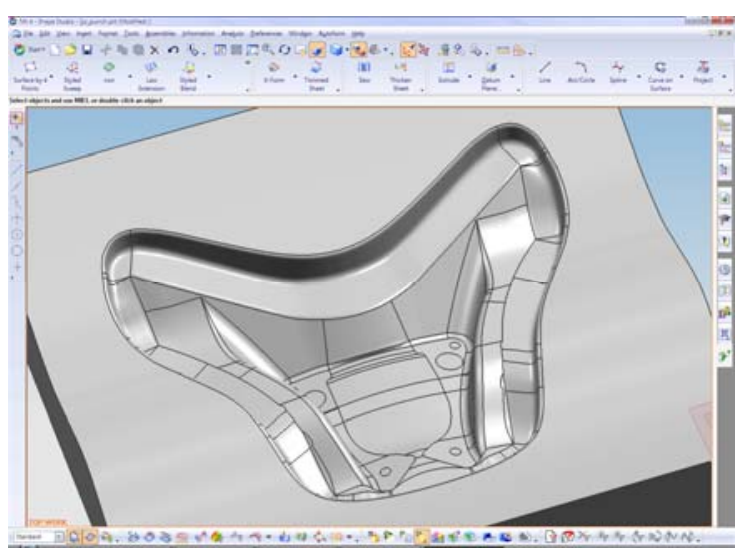

Fig. 12. Solid model of the die created from the reference geometry using the AFUG interface

\section{CONCLUSIONS}

Computer aided engineering has a vital and central role in the recent developments in sheet metal forming concerning the whole product development cycle. The application of various methods and techniques of CAE activities resulted in significant developments: the formerly trial-and-error based workshop practice has been continuously transformed into a sciencebased and technology driven engineering solution.

In this paper, an integrated approach for the application of knowledge based systems and finite element simulation is introduced. Applying this knowledge and simulation based concept for the whole product development cycle - from the conceptual design through the process planning and die design as an integrated CAE tool - provides significant advantages both in the design and in the manufacturing phase. Sheet metal forming simulation results today are already reliable and accurate enough that even tryout tools and the time consuming tryout processes may be eliminated or at least significantly reduced. Thus, the integrated solution described in this paper results in significantly shorter lead times, better product quality and as a consequence more cost-effective design and production.

\section{ACKNOWLEDGEMENTS}

This research work was jointly financed by the Hungarian Academy of Sciences (MTA) and the National Science Foundation (Ref. No.: OTKA NI 61724). This financial support is gratefully acknowledged. 


\section{REFERENCES}

[1] S.K. Sitaraman, T. Altan: A Knowledge Based System for Process Sequence Design in Sheet Metal Forming, J. of Mat. Proc. Techn. (1991) pp. 247-271.

[2] N. Alberti, L. Cannizaro, F. Micari: Knowledge Based Systems and FE Simulations in Metal Forming Processes, Annals of CIRP, v.40. (1991) pp. 295-298.

[3] L. Eshelby, M. Barash, W. Johnson: A Rule Based Modelling for Planning Axisymmetric Deep-drawing, Int. J. of Mech. Sciences. (1988) pp. 1-113.

[4] Makinouchi, A.: Sheet Metal Forming Simulation, J. Materials Processing Technology v.60. (1996) pp. 19-26.

[5] A. E. Tekkaya: State of the art of Simulation in Sheet Metal Forming, J. Mat. Proc. Techn., v.103. (2000) pp. 14-22.

[6] T. Altan et al: Simulation of Metal Forming Processes, $6^{\text {th }}$ ICTP Conf., Nuremberg, 1924. September 1999. v. 1. p. 23.

[7] M. Tisza: Numerical Modelling and Knowledge Based Systems in Metal Forming, ICTP Conf., Nuremberg, 19-24. Sept. 1999. in Advanced Technology of Plasticity, 1999. v. 1. pp. $145-154$.

[8] M. Tisza: A Complete CAD/CAM System for Metal Forming, $2^{\text {nd }}$ Int. Conf. on CAD/CAM and Robotics, London, 22-26. August 1990. pp. 110-117.

[9] M. Tisza: Expert System for Sheet Metal Forming, J. of Mat. Proc. Techn. (1995) pp. 423-432.

[10] C. T. Wang: Advanced Stamping Simulation Technology - State of Business and Industrial Prospect, Numisheet Conf., Besancon, 13-17. Sept. 1999. pp. 250-256.

[11] T. Altan, V. Vasquez: New Concepts in Die Design - Physical and Computer Modelling, J. of Mat. Proc. Techn., v. 98. (2000) pp. 212-223.

[12] C. T. Wang: Evolutions of Advanced Stamping CAE, NumiSheet2005 Conf., 19-24. September 2005. pp. 78-82.

[13] A. Tang et al: CAE Based Die Face Engineering Development, NumiSheet2005 Conf., 19-24. Sept. 2005. pp. 50-60.

[14] C. T. Wang: A Road Map for Simulation-Guided Die Try-out and Stamping Process Control, NumiSheet2005 Conf., 19-24. September 2005. pp. 66-69.

[15] C. T. Wang: An Industrial Outlook for Springback Predictability, NumiSheet2002, Jeju island, Korea, 21-25. Oct. 2002. pp. 597-604.

[16] M. Tisza: Numerical Modelling and Simulation in Sheet Metal Forming, Journal of Materials Processing Technology, v.151. (2004) No. 1-3. pp. 58-62.

[17] A. Andersson: Information Exchange within Tool Design and Sheet Metal Forming, J. of Engineering Design, 2001. v. 12. No. 4. pp. 283-291.

[18] A. Andersson: Comparison of Sheet Metal Forming Simulation and Try-out Tools in Design of Forming Tools, J. of Engineering Design, v. 15. (2004) No. 6. pp. 551-561.

[19] M. Tisza: Numerical Modelling and Simulation: Academic and Industrial Perspectives, Materials Science Forum, v. 473-474. (2005) pp. 407-414.

[20] M. Tisza: Rapid Parametric Process Design using FEM, Advanced Materials Research, v. 6-8. (2005) pp. 235-240. 